\title{
Android Based Japanese Handwriting Application
}

\author{
Yulia \\ Department of Informatics \\ Petra Christian University \\ Surabaya, Indonesia
}

\author{
Justinus Andjarwirawan \\ Department of Informatics \\ Petra Christian University \\ Surabaya, Indonesia
}

\author{
Malvin Yuwono Kurniawan \\ Department of Informatics \\ Petra Christian University \\ Surabaya, Indonesia
}

\begin{abstract}
Japanese language writing system is divided into 2 forms, namely Hiragana and Katakana. Both are characters that each have their own usefulness as a basic word. Due to the basic character, the Japanese language is very similar to other languages in general that has the alphabet as a base word. The most effective way for a person's ability to memorize is to use a media of learning interesting and interactive. Among the form of technology-based learning media are quite friendly with the people at home and outside the home, for example, smartphones are already widely used by all levels of society, both in cities and villages. Therefore, interactive learning applications based on Android is most needed.
\end{abstract}

Keywords: Android, hiragana, japanese, katakana, learning application

\section{INTRODUCTION}

We ask that authors follow some simple guidelines. This document is a template. An electronic copy can be downloaded from the journal website. For questions on paper guidelines, please contact the conference publications committee as indicated on the conference website. Information about final paper submission is available from the conference website

Japanese writing system is divided into two parts, namely Hiragana and Katakana. Hiragana is the basic language used only for words that are not a foreign language. Meaning it is not to take accent pronunciation or writing of English or German. Unlike the Hiragana, Katakana is used to write the word uptake whose use has been integrated and generally accepted. So in writing Japanese words, a loan word or not can be distinguished by writing letters. Based on this fact, in this study will prioritize learning Hiragana because it is considered as the basic material for teaching beginners level.

However, from the difference, Katakana and Hiragana have the exact same pronunciation, and it makes no difference. This is evidenced in both the letter in the Romaji version. Romaji or may be called by the Roman script is writing the letters using the Latin alphabet.

When counting the number of basic letters in Hiragana and Katakana, each of them has 46 letters. In total there are 92 types of letters, this makes the learning ineffective because it accumulates. Therefore, the material will be divided into two sessions Hiragana and Katakana. This makes the material divided into two, but 46 letters also included a lot to be learned as well. To make learning more effective, 46 letters were made into a learning package (lesson). The grouping of the letters based on the sequence chart is divided equally into 10 lessons for both Hiragana and Katakana.

Learning of reading and writing begin in childhood using various methods. Children learn to recognize letters which then can read and write. (Štorková \& Kisela, 2015). Nowdays, multimedia devices have been widely used as an educational technology tool (Malik \& Agarwal, October 2012) (Pea, July 1991). The children can gain knowledge and then they can try to solve the problem from the test case. And nowdays, most of the students have their own smartphones and tablets. Given these reasons, this research was made an interactive learning media by using Android.

\section{THEORETICAL BASIS}

\subsection{Japanese Language Curriculum}

Japanese language is written using the basic letters called Kana. Kana letter is divided into three, namely Hiragana, Katakana, and Kanji (Stewart \& Murotani, 2012). The third type of Kana's own use each and different writing. Hiragana is used to write the words that does not use the original Japanese kanji, as Ohayou which means good morning and arigatou which means thank you. Katakana is used for transliteration from foreign languages to Japanese, for example konpyuuta which means computers and orenji which means orange (Center, 2013).

The shape of the Hiragana letter can be seen in Figure 1.

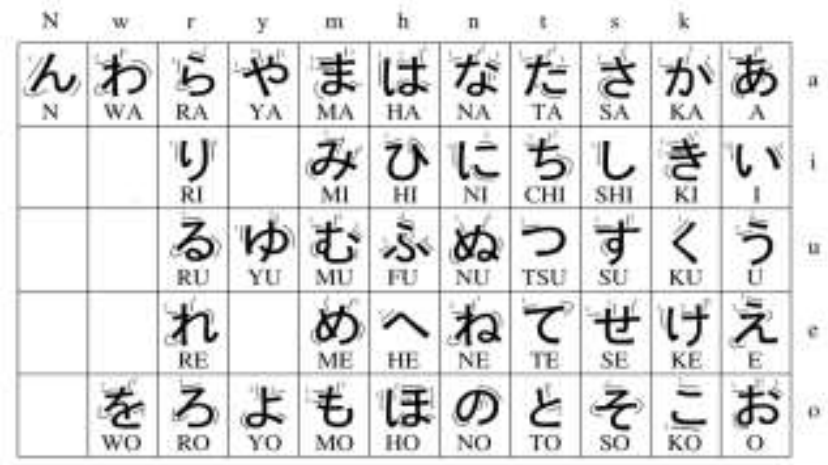

Figure 1. Hiragana Chart (Budo Shugyosha)

Hiragana is basically used to say 46 types of sound in the Japanese language. Hiragana should be studied first before studying Katakana because it will facilitate the learning of Katakana. 
Katakana is used to write transliteration of foreign languages to Japanese, for example konpyuuta means computers and orenji which means orange. The shape of the katakana can be seen in Figure 2.

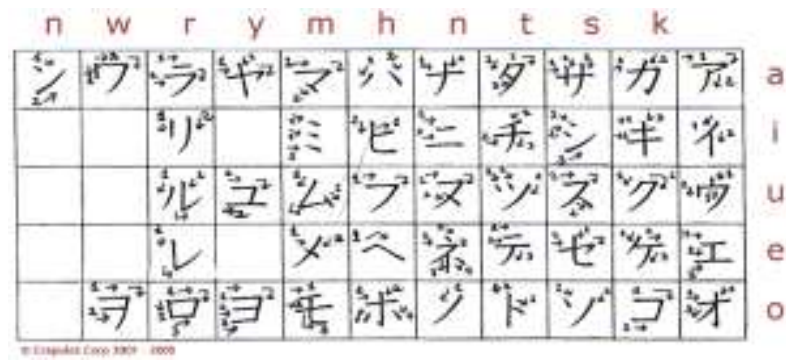

Figure 2. Katakana Chart (Crapules Corp)

Katakana also has a total of 46 different letters from Hiragana. However, when viewed, the typeface has the exact pronunciation. Therefore learning should be done separately.

\subsection{Android Mobile Application for Education}

The touch screen is used as a user interface for most mobile devices. Even notebook which use a keyboard and mouse as input devices are equipped with a touchpad. Touch Screen easily become very affordable for the general population due to greater expansion and lower prices. Another advantage is that these devices will replace positioning device such as a mouse or a touchpad in near future. The other advantage is an intuitive gestures recognition which simply expresses the intended requirement. (Štorková \& Kisela, 2015).

A mobile application is software designed for mobile operating systems. From the survey of the use of mobile application to a group of 39,000 Purdue University students, $43 \%$ of students use Android and $40 \%$ use iOS. (Bowen \& Pistilli, 2012). And based on kantarworldpanel.com report, by the end of 2014, Android's market share amounted tp of $68.4 \%$ across Europe.

Android is built using object oriented theory that divides its constituent elements into shaped objects that can be reused / reusable. In order to make the application well, it is obvious for the developers to need to know the architecture of Android OS along with the elements. Figure 3 is a schematic representation of the distribution of elements on the Android architecture. (Harahap, 2014)

\begin{tabular}{|c|c|c|c|c|}
\hline \multicolumn{5}{|c|}{ Applications and Widgets } \\
\hline Home & Contacts & Browser & Widgets & Your App Here \\
\hline \multicolumn{5}{|c|}{ Application Framework } \\
\hline $\begin{array}{l}\text { Activity } \\
\text { Manager }\end{array}$ & $\begin{array}{l}\text { Window } \\
\text { Manager }\end{array}$ & $\begin{array}{l}\text { Content } \\
\text { Providers }\end{array}$ & View System & $\begin{array}{l}\text { Notification } \\
\text { Manager }\end{array}$ \\
\hline $\begin{array}{l}\text { Package } \\
\text { Manager }\end{array}$ & $\begin{array}{l}\text { Telephony } \\
\text { Manager }\end{array}$ & Resource & $\begin{array}{l}\text { Location } \\
\text { Marnager }\end{array}$ & $\begin{array}{l}\text { Sensor } \\
\text { Manager }\end{array}$ \\
\hline Libraries & & & \multirow{3}{*}{\multicolumn{2}{|c|}{$\begin{array}{l}\text { Android Runtime } \\
\text { Core Libraries }\end{array}$}} \\
\hline $\begin{array}{l}\text { Surface } \\
\text { Manager }\end{array}$ & $\begin{array}{l}\text { Media } \\
\text { Framework }\end{array}$ & SQLite & & \\
\hline OpenGL | ES & Freetype & Webkit & & \\
\hline SGL & SSL & libc & & \\
\hline \multicolumn{5}{|l|}{ Linux Kernel } \\
\hline Display Driver & $\begin{array}{l}\text { Bluetooth } \\
\text { Driver }\end{array}$ & Camera Driver & $\begin{array}{l}\text { Flash Memory } \\
\text { Driver }\end{array}$ & $\begin{array}{c}\text { Binder (IPC) } \\
\text { Driver }\end{array}$ \\
\hline Keypad Driver & USB Driver & WiFi Driver & Audio Drivers & $\begin{array}{l}\text { Power } \\
\text { Management }\end{array}$ \\
\hline
\end{tabular}

Figure 3. Android Architecture (Harahap, 2014)

\section{SYSTEM DESIGN}

\subsection{System Architecture}

In this process there are three main components that interact namely user / users, Android, and the local database. Database function stores the state of learning in this application. In this application, Android will call files that exist on the Android system. Later there is only a read process on the Android device to the existing data in the database. Users will only be able to input in the form of swipe through a smartphone that will be checked to generate an output.

\subsection{Process Design}

Based on the flow of data on Android applications that have been designed, designing a data flow diagram that can be seen clearly in Figure 4. When the application is run the user will be taken directly to the Main Menu. In this menu the user is free to make choices. There are four choices of Play, Study, Achievement, and Setting.

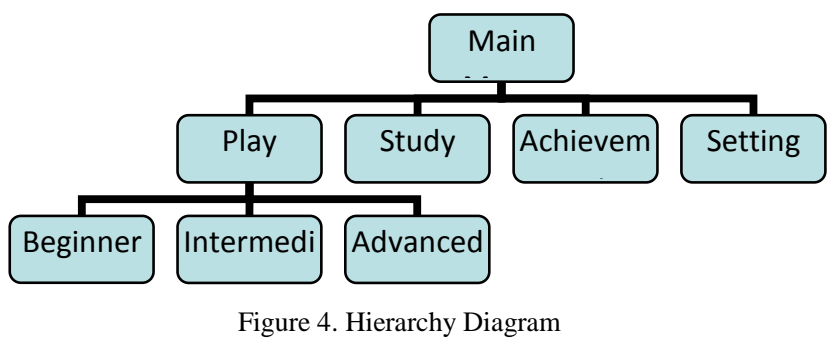

\subsubsection{Play Process Design}

On this menu the user will play with basic letters corresponding learning materials. This section is divided into two types, namely Hiragana and Katakana letters. However, before the user logs in to a selection of letters, user's study progress will be checked first. When eligible to play the notification to use Study menu will not appear. There is also a difficulty level provided to test and challenge the user to write the letter. Each level has a different difficulty and which particular features of its own. Checking will happen which is the input process in the form of swipe and keystrokes sound. Segment swipe input process can be seen in Segment 1. To create a page that can detect and animate swipe, swipe is needed in the form of a layout canvas governing GestureOverlayView (Patterns-Gestures) (Canvas and Drawables). These layout functions are useful for creating animated swipe on the layout.

Segment 1. Swipe Input Process

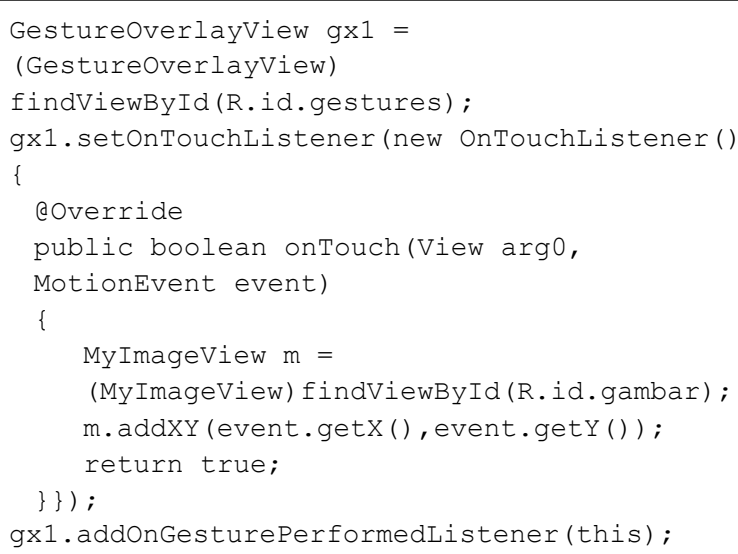




\subsubsection{Study Process Design}

In this menu the user can learn about Hiragana and Katakana. When users enter this menu there is a list of Hiragana which will appear as it is set as the default list. Users can turn to writing Katakana or Romaji to display different letters. When users change the case Romaji, Kana button will appear and vice versa.

\subsubsection{Swipe Tolerance Design}

In this application, tolerance applied to the user that the application is not rigid-selling, which means sticking to the exact point that has been determined. Given this tolerance, the application is expected to be more friendly to the user and can tolerate user error within the tolerance limits that have been determined.

Calculation of tolerance is based on the smartphone screen resolution which is owned by the user. The exact point will be large compared to the maximum of the screen both in length and width. Then, the exact point will create a tolerance range specified by the developer.

To do that we need a formula and mathematical calculation steps. If desired, tolerance by 25 pixels at the point $(x, y)$. Tolerance is based on screen resolution that is $(\alpha, \beta)$. Therefore point $(\mathrm{x}, \mathrm{y})$ has a tolerance of $\pm \frac{25}{\alpha}$ for $\mathrm{x}$ and $\pm \frac{25}{\beta}$ tolerance of:

$$
\text { - } \mathrm{a}-\frac{25}{\alpha} \leq x_{t} \leq \mathrm{a}+\frac{25}{\alpha} \text { for } \mathrm{x}-
$$

coordinate.

$$
\text { - } \mathrm{b}-\frac{25}{\beta} \leq y_{t} \leq \mathrm{b}+\frac{25}{\beta} \text { for } \mathrm{y}-
$$

coordinate.

\section{RESULT}

When a user runs the application, the user will be directed to the main menu. This section is divided into four choices of play to play, to learn the letters that will be played, providing the information about the percentage of achievement of learning undertaken, and settings that can be set by the user accordingly. Here is a picture of the Main Menu design in Figure 5.

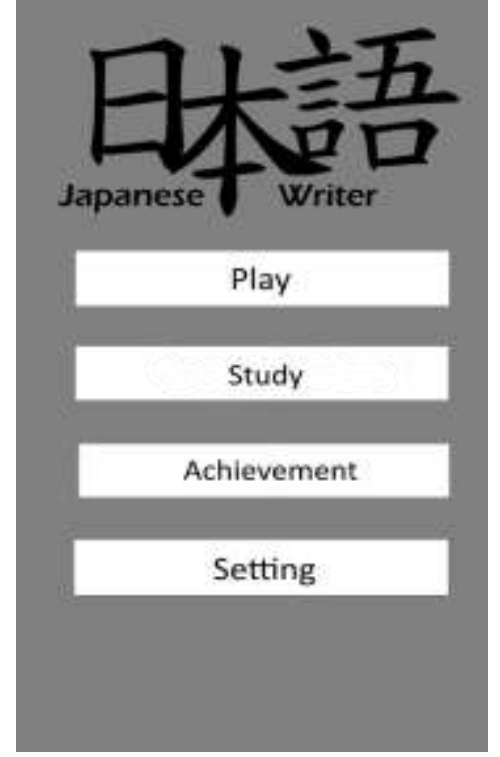

Figure 5. Menu

Study Menu is where users learn Hiragana and Katakana freely. In this section, the user can select the tab Hiragana or Katakana. List of characters can be selected in accordance with the wishes of the user. When the user selects a specific letter then it will go to another layout to try to write the letter. In that section, included line guide help that can be on / off and no key sound for pronunciation of the letters that are printed. To return to the menu list of letters the user can press the back button on the smartphone user. In order to clearly see more, a list of the letters can be seen in Figure 6 and to try to see the letters which can be seen in Figure 7 .
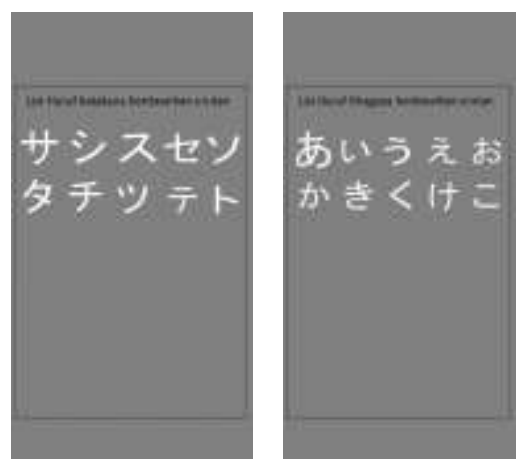

Figure 6. Layout List of Menu Study
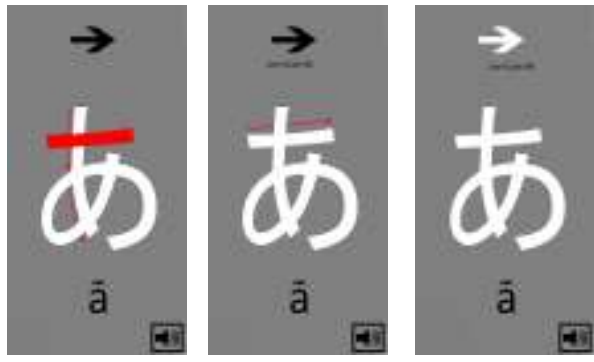

Figure 7. Layout of character experiment in Study Menu

The play menu is generally divided into two parts, namely Hiragana and Katakana. Users are advised to complete Hiragana first. If users choose Katakana then a pop-up warns to complete Hiragana first. Each letter was 48 so it will be divided into 10 separate lessons. Players must complete the first lesson which will open the second lesson, and the lesson 
2 will open lesson 3 and so on. Figure 8 below is the form of the game menu.
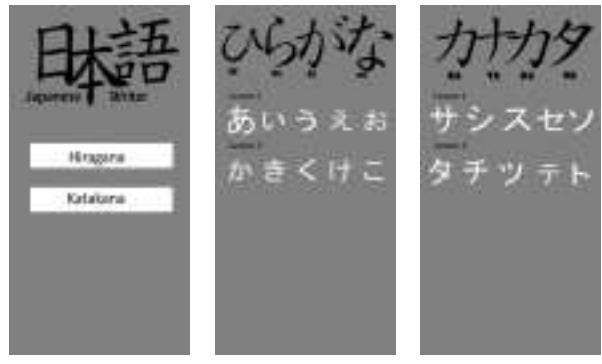

Figure 8. Game Menu

Before the player chooses a selection of lesson to be played, the player is required to choose the level of difficulty that has been provided, namely beginner, intermediate and advanced. At the entry level user on the instructions given in the form of a pointer to swipe assistance in accordance with the letters displayed. To view the beginner level games can be seen in Figure 9.

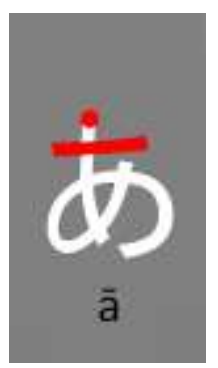

Figure 9. Beginner Level Game Layout

This image is the hardest difficulty level. Sounds are only played at the beginner level only. This mode also uses a countdown, when the user is not able to resolve the case then the user is determined to have failed. To see mid-level games, they can be seen in Figure 10.

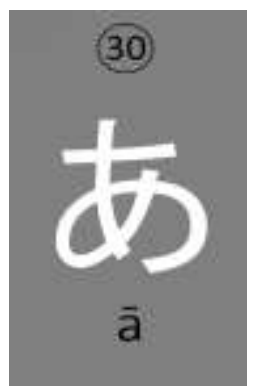

Figure 10. Advanced Level Layout

Writing version can be set in the settings menu, when this version will only be shown in outline is activated when the first letter appears. When the user has to swipe, outline will disappear completely. However, if the user inputs the correct picture, it will remain updated. Changes in study mode can be seen in Figure 11.

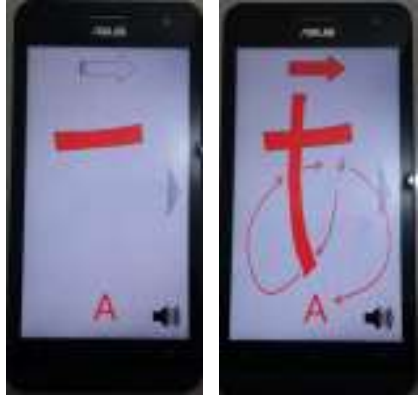

Figure 11. Write Version Study Page

\section{OBSERVATION}

To determine user satisfaction scale, a survey is conducted. This survey is addressed to the general public as many as 20 people aged 17-21 years.

Table 1 is a collection of respondents about the Japanese language ability, especially Hiragana and Katakana.

Table 1. Japanese Language Ability Data

\begin{tabular}{|l|l|}
\hline \multicolumn{2}{|c|}{ Japanese Language Ability Respondents } \\
\hline Yes & 14 \\
\hline No & 6 \\
\hline
\end{tabular}

It can be concluded that:

- For application interface, one respondent (5\%) gives less satisfied respond but three respondents (15\%) quite satisfied, fifteen respondents $(75 \%)$ are satisfied and one respondent $(5 \%)$ is very satisfied. This proves that the existing interface can be accepted and used properly by the user.

- For the level of ease of the application, the results obtained by one respondent $(5 \%)$ gives a value of less satisfied, but there are four respondents $(20 \%)$ give a value quite satisfied, eight respondents $(40 \%)$ give satisfied and seven respondents (35\%) are very satisfied. Thus the conclusion of this application was considered easy to use.

- $\quad$ For the learning process help, there are four respondents $(20 \%)$ give a value quite satisfied, six respondents $(30 \%)$ are satisfied and ten respondents (50\%) give very satisfied. Thus it can be concluded that this application can help the learning process well.

- For the features available in this application, eight respondents $(40 \%)$ give a value quite satisfied, nine respondents $(45 \%)$ are satisfied and three respondents $(15 \%)$ are very satisfied. Thus, the features available in this application are feasible and adequate.

- For the assessment of the application, there are two respondents $(10 \%)$ give a value quite satisfied, fifteen respondents $(75 \%)$ are satisfied and three respondents $(15 \%)$ are very satisfied. It can be concluded that the assessment of the application is good enough.

It has been conducted a testing on applications regarding the features provided. This trial aims to determine whether the application can run properly without error. Testing conducted with several different device specifications and Operating System (OS). The specifications of the device to be used are:

1. Samsung Galaxy Mega I9150, Android 4.2.2 (Jelly Bean), 5.8 inches (540 x 960 pixel), Dual-core $1.4 \mathrm{GHz}$, 8GB, 1.5 GB RAM. 
2. Asus Zenfone 5 A500CG, Android 4.4.2 (KitKat), 5.0 inches (720 x 1280 pixel), Dual-core $2 \mathrm{GHz}, 8 \mathrm{~GB}, 2 \mathrm{~GB}$ RAM.

3. LG G2 D802, Android 4.4.2 (KitKat), 5.2 inches (1080 x 1920 pixel), Quad-core 2.26 GHz Krait 400, 16 GB, 2 GB RAM.

All of the three devices above applications can run smoothly, the difference in resolution is not a problem at the interface layout. This is because the layout made is already responsive and adaptable in various resolutions.

\section{CONCLUSIONS}

After creating and designing applications of Hiragana and Katakana learning, it can be drawn to several conclusions:

1. With the results of experiments on several OS and API, it can be concluded that the application can run on OS JellyBean up with Lollipop and the API 16-21.

2. The process of checking if the swipe input based on predictions prediction score is too high, the system will tend to blame the user and if it is too small a system will tend to justify the user.

3. With this application, users can learn writing characters that became the basis of the Japanese language and can try to write these letters.

\section{REFERENCES}

[1] Bowen, Kyle and Pistilli, Matthew D. 2012. Student Preferences for Mobile App Usage. Purdue University : Educause, 2012.

[2] Budo Shugyosha. [Online] [Cited: 5 Jan 2015.] http://www.budoshugyosha.com/wpcontent/uploads/2013/03/table_hiragana.png.
[3] Canvas and Drawables. [Online] [Cited: 10 Feb 2015.] http://developer.android.com/guide/topics/graphics/2dgraphics.html.

[4] Center, Meguro Language. 2013. Hiragana Katakana Workshee. [Online] 2013. [Cited: 5 1 1 2015.] http://www.mlcjapanese.co.jp/Download/HiraganaKatak anaWorkSheet.pdf.

[5] Crapules Corp. [Online] [Cited: 2 Jan 2015.] http://www.crapulescorp.net/japonais/syllabaires/ trace_katakana.gif.

[6] Harahap, Nazruddin Safaat. 2014. Android Pemrograman Aplikasi Moblie Smartphone dan Tablet PC Berbasis Android. Bandung : Informatika, 2014.

[7] Learning Through Multimedia. Pea, Roy D. July 1991. July 1991, IEEE Computer Graphics and Application, pp. 57-67.

[8] Patterns-Gestures. [Online] [Cited: 20 Feb 2015.] https://www.google.com/design/spec/patterns/gestures.ht $\mathrm{ml}$.

[9] Stewart, Anne Matsumoto and Murotani, Noriko. 2012. Kodansha's Hiragana Workbook: A Step-by-Step Approach to Basic Japanese. Japan : Kodansha, 2012.

[10] Tablet as a new interactive tool for education paleography. Štorková, Pavla and Kisela, Jiri. 2015. 2015, Procedia - Social and Behavioral Sciences 174, pp. $3164-3169$

[11] Use of Multimedia as a New Educational Tool - A Study. Malik, S and Agarwal, A. October 2012. October 2012, International Journal of Information and Education Technology Vol 2 No 5, pp. 468-471. 